\title{
Human Relations
}

http://hum.sagepub.com

\section{Organizing Frameworks in Emerging Organizations: A Cognitive Approach to the Analysis of Change Jan Löwstedt \\ Human Relations 1993; 46; 501 \\ DOI: $10.1177 / 001872679304600405$}

The online version of this article can be found at:

http://hum.sagepub.com/cgi/content/abstract/46/4/501

\author{
Published by: \\ (5) SAGE Publications \\ http://www.sagepublications.com \\ On behalf of: \\ (1) \\ The Tavistock Institute
}

Additional services and information for Human Relations can be found at:

Email Alerts: http://hum.sagepub.com/cgi/alerts

Subscriptions: http://hum.sagepub.com/subscriptions

Reprints: http://www.sagepub.com/journalsReprints.nav

Permissions: http://www.sagepub.com/journalsPermissions.nav

Citations (this article cites 17 articles hosted on the

SAGE Journals Online and HighWire Press platforms):

http://hum.sagepub.com/cgi/content/refs/46/4/501 


\title{
Organizing Frameworks in Emerging Organizations: A Cognitive Approach to the Analysis of Change
}

\author{
Jan Löwstedt ${ }^{1,2}$
}

\begin{abstract}
This article presents a study designed to relate the way decision makers think about organizing to emerging changes in organizations. The complexity and content of the organizing frameworks of key actors in three cases of introduction of computer aided design were analyzed. This resulted in a typology describing actors as analysts, facilitators, or organizers. A correspondence was found between the way these actors thought about organization and the emerging organizations observed in three cases. The study is used to develop a cognitive actor's approach to organizational change.
\end{abstract}

KEY WORDS: change; organizing; cognition; frameworks; technology.

\section{INTRODUCTION}

Technological changes are often assumed to change the structure of the organization in one direction or another (Child, Ganter, \& Kieser, 1987, p. 102). Computer Aided Design (CAD) is frequently referred to as an example of a technology which is expected to alter dramatically the work of engineers and their relations to other functions within the firm (Cooley, 1977; Berner, 1981; Finne, 1982). Maybe there is no single technology that has given rise to as much prejudice and wishful thinking about future organization as CAD (Löwstedt, 1988).

The idea that organizational structures in surviving organizations result from necessary adaptation to technology (or other contingencies such as size) used to be referred to as contingency theory. However, there has been mounting theoretical criticism of the contingency theory assumption that it is possible to formulate general propositions as to what would be

${ }^{1}$ Stockholm School of Economics, Sveavagen 65, Box 6501, 11383 Stockholm, Sweden.

${ }^{2}$ Requests for reprints should be addressed to Dr. Jan Löwstedt, Stockholm School of Economics, Sveavagen 65, Box 6501, 11383 Stockholm, Sweden. 
the best form of organization (Silverman, 1970; Crozier \& Friedberg, 1980; Schreyogg, 1980; Löwstedt, 1985). Results from empirical studies also show that particular technologies do not engender particular organizational solutions. The technological imperative is questioned by the notion of organizational choice (Trist \& Bramforth, 1951; Trist et al., 1963; Child, 1972; Brytting \& Löwstedt, 1986; Child \& Loveridge, 1990).

A comparative study was designed to research such choices in companies introducing CAD. Case studies were conducted in three Swedish engineering companies to study how they organized their use of the technology. The results show major differences.

One early conclusion from the study was, however, that the explicit choices made were largely technical, not organizational. To explain the differences in how the companies organized computer-aided design work, it was necessary to look beyond the explicit reasons given for their choices in the adaptation process. Therefore, the study continued with a second phase to investigate the extent to which information about cognitive structures held by significant actors in these processes could contribute to the understanding of differences between the cases. This aims at supplementing earlier theoretical assumptions by Downey \& Brief (1986) with empirical data that highlight the importance of the cognitive structures of actors who function as "organizations designers" in change processes.

To provide a theoretical basis for the study and the interpretation of the results, an approach to organizational change focusing on key actors is presented. After an analysis of the two-phase study, this framework is developed into a cognitive actors approach to organizational change.

\section{COGNITION AND CHANGE}

One reason for the fogginess which tends to characterize discussions of the significance of new technology for changes in organizations is perhaps the fact that it is often unclear what changes the new technology is expected to engender. This lack of clarity indicates that theory in this area is underdeveloped (Helgeson, 1986; Child \& Loveridge, 1990). One approach to reducing the belt of mist is to bring to bear the growing interest in cognitive theorizing in organization research. An alternative approach involves taking a closer look at the classification and meaning of technology (Perrow, 1967; Meredith \& Hill, 1987; Nemetz \& Fry, 1988, etc). The main emphasis here is in line with the first approach, to explore the impact of cognitive structures on organizational change.

According to structuration theory (Giddens, 1984) technology is not an exogenous determining force, but an opportunity which releases social dynamics in a process in which the existing organization is modified or 
reinforced. Human beings involved in such organizing processes become "social carriers of technology and change" (Edquist \& Edqvist, 1980). They are not merely passive bearers of new technology. On the contrary, significant actors may be assumed to affect organizational design through their cognitive structures (Downey \& Brief, 1986).

In his study of how work and the work organization were structured when CT-scanners were introduced at two hospitals, Barley (1986) emphasizes that the organizational differences observed can be understood in terms of "structuring processes." Differences emerge because structures are produced and reproduced "by situated action." Emerging structures are determined by the interaction between the occupational groups concerned. The importance of actors in terms of decision makers is de-emphasized in favor of personnel directly involved in the work process. "Thus from the perspective of structuring theory, decision makers may in fact influence the evolution of interaction orders, but the structural consequences of their decisions are likely to be unanticipated" (Barley, 1986, p. 107). In a cognitive approach to organizational change implicit or explicit thoughts are supposed to guide such interaction.

\section{Cognitive Structures}

Scott (1962) defined a cognitive structure as the individual's entire cognitive world, the fruit of all his interaction with his environment. Such structures, comprising fairly stable and permanent components, are often called cognitive maps.

Tolman (1948) is usually given credit for first employing the concept of cognitive map. In the thirties, Tolman studied how rats learned to find their way through complicated labyrinths. He found that a rat passing through a labyrinth did not learn a sequence of left turns, right turns and so on, but instead developed a mental image of the labyrinth, a cognitive map (Atkinson et al., 1981, p. 283).

In organization theory, the mapping concept was mentioned by Simon in the fifties (1952). However, there are relatively few empirical studies of human cognitions in real-life situations in organizations. Today there are a growing number of studies in which the cognitive mapping concept is used as a collective term to encompass the collection of organizational experience by individuals into patterns of personal knowledge (Weick \& Bougon, 1986; Huff, 1990; Laukkanen, 1990).

Argyris and Schon (1978) consider that people must have points of reference if they are to understand what happens in an organization and that cognitive maps may in fact provide such points of reference. 
This is the function of organizational maps. These are the shared descriptions of organization which individuals jointly construct and use to guide their own inquiry. They include, for example, diagrams of work flow, compensation charts, statement of procedures, even the schematic drawings of office space. A building itself may function as a kind of map, revealing patterns of communication and control. Whatever their form, maps have a dual function. They describe actual patterns of activity, and they are guides to future action. As musicians perform their scores, members of an organization perform their maps (p. 17).

Zajonc (1960) emphasizes that cognitive structures are related to objects, individuals, events, occurrences, or phenomena at a given point in time. The structures consist of certain elements coordinated into "personal constructs" (Kelly, 1955). The sum of all the elements forms the individual's cognitive universe (Zajonc, 1960). The structures are the result of previous experiences. In processing information about a given object, phenomenon, or event, a person will select the cognitive structure that seems appropriate to the task. For example, Zajonc's experiments showed that different cognitive structures were tuned in when the individual was expected to be a receiver or a sender of information, and depending on who he was interacting with.

\section{Cognitive Processes}

More differentiated cognitive structures tend to evolve as the person gains experience in a given area (Witkin et al., 1962; Fiske \& Taylor, 1984). Just as there are theories of learning that stress individual experience (Kolb, 1976) or social learning (Bandura, 1977), there are also different ways to look upon the formation of cognitive structures. Kelly's theory of "personal constructs" (1955) might be said to represent an inside view. Kelly compares the individual to a researcher who is trying to create contexts and make sense of the reality he or she experiences by constructing theories. The theories are continually tested, and are modified on the basis of new experience. An alternative approach emphasizes interaction with other people. It holds that cognitive structures are mainly formed in a social process, with individuals attributing causes to what they see happening in their environment (Kelley, 1971). This is mainly a sense-making process in which observations are explained. Cognitive structures are therefore not tested and very seldom revised (Brief \& Downey, 1983).

There are arguments at the individual, group, and organizational levels in support of this kind of cognitive stability. At the individual level, this stability is expressed, for example, in terms of cognitive style (Kolb, 1976) and in cognitive biases (Tversky \& Kahneman, 1974). For example, experiments have demonstrated that people are reluctant to reject hypotheses, or problem solutions, which they have arrived at early in a problem-solving 
process (Wason, 1960). Another example is unwillingness to consider other aspects of a problem than those that have been identified in the information gathering and diagnosis stages of problem solving (Miller, 1956).

At the group level, interest centers on the alliances which emerge in interactions between people. This is a question of social psychological mechanisms expressed, for example, in various forms of pressure to conform. It is also a matter of what are known as "conventions" in game theory (all individuals in a system pursue a certain strategy because everyone else does). The convention is stable because anyone choosing another strategy runs a serious risk of losing (Skogh, 1989).

At the organizational level, Danielsson (1983) considers that solutions generated to deal with specific financial or organizational problems do not disappear even if they have been discarded, but remain intact for a long time. Danielsson terms such residue solutions "sediment," feeling that generalizations are often extended into areas not related to the original solutions. Other authors have described how projects and companies survive despite many reasons for their collapse - as in the case of "surviving failures" (Persson, 1979).

\section{Organizing Frameworks: A Definition}

Just as the researcher uses organization theories to understand organizational phenomena, members of an organization have their own ideas about how organizations can and should function. People's actions are therefore not only steered by simple behavioral rules of the "turn left," "turn right" type, but also by the frameworks they develop, on the basis of their experience in an organization, about the functioning of organizations in general. Such cognitive structures are termed "organizing frameworks."

Bowey (1983) analyzed to what extent the views of a group of managers and students on questions concerning the management and organization of an operation complied with four basic organization theories (Classical Management, Systems Perspective, Pluralist/Political Perspective, and Human Needs Orientation). Bowey's results indicate that their past experience influenced people's preference for the four theories. However, Bowey does not distinguish clearly between object-specific and general theories or models.

The object relationship of cognitive structures was described by Zajonc. From Bowey's study, it may be concluded that actors also employ deeper, more fundamental structures of a more general nature than these object-related cognitions. One indication of this might be our readiness to generalize. One example of this is the "halo effect," which describes our 
Table I. A Typology of Cognitive Structures

\begin{tabular}{lll}
\hline & Subjective rationale & Local rationale \\
\hline General & Organizing framework & Dominant organization idea \\
Object-specific & Organization image & Local theory \\
\hline
\end{tabular}

tendency to allow our impressions of a person in one area to influence our assessment of the person in quite a different context (Thorndyke, 1920). Another example is a study by Freeman et al. (1988) of human ability to process information about their social relationships. They conclude that "the correspondence between observed social behavior and people's mental maps is startlingly close" (p. 423). Humans have poor memory for particular occasions of interaction, although they seem to bias their recall to fit in with general patterns.

The existence of such fundamental generative mechanisms supports a distinction between object-specific ideas about organizations - the image of the organization - and deeper, more fundamental structures covering organizations and organizing - the organizing framework. The organizing framework as it applies to human beings is an unevenly developed theory about how organizations function and how they change.

In contrast with Bowey, who builds on accepted theories and studies people's preferences for propositions generated by such theories, a typology is suggested where the distinction is between cognitions that are object specific or general on the one hand, and subjective or intersubjective on the other (Table I). The typology is used to clarify the meaning of the concept of "organizing framework," which is elaborated below. The characteristics of the other concepts is beyond the scope of this paper.

\section{The Organizing Process}

The organizing process can now be defined as the process in which an organization, or part of it, develops and changes its structure, either gradually or in dramatic leaps. It is a type of meta-process which generates more concrete processes, such as those involving the actual work (the work process) or the transfer of goods to customers in exchange for money (the exchange process).

This view of the origins and change of structures is not unlike what Giddens (1984) calls "structuration theory" and Barley's (1986) "process of structuring." In both cases, the focus of interest is directed toward a structure-generating process, rather than the change process itself. 
Structuring theory thus departs from previous approaches to the study of technology by postulating that technologies are social objects capable of triggering dynamics whose unintended and unanticipated consequences may nevertheless follow a contextual logic. Technologies do influence organizational structures in orderly ways, but their influence depends on the specific historical process in which they are embedded. To predict a technology's ramifications for an organization's structure therefore requires a methodology and a conception of technical change open to the construction of grounded, population-specific theories (Barley, p. 107).

\section{PHASE 1: THREE CASE STUDIES ON THE INTRODUCTION OF COMPUTER-AIDED DESIGN}

\section{Method}

Three Swedish engineering firms that adopted CAD early on were chosen for intensive case studies. They were all known as pioneers, and in this respect far ahead of most companies in their sector. These companies had much in common when it came to characteristics such as: type of markets, products, customers, owners, localization, and size. They also implemented $\mathrm{CAD}$ in the same year and were studied 3 years after the introduction of CAD.

The case studies are based on interviews, written documents, and two questionnaires. In total, 70 interviews were conducted in the companies. People at all levels in the design department were interviewed representing both users and non-users of CAD. People in the sales, production, and finance departments were also interviewed to evaluate consequences seen to derive from the introduction of CAD. The interviews were supplemented by two questionnaires: one to tap engineers' attitudes to their work and an "activity follow-up" which surveyed their work activities during 2 weeks time (see Löwstedt, 1986, 1988). Sixty engineers, a matched sample of CAD-users and non-users in the three companies, participated in the questionnaire study.

Detailed descriptions of company-wide organization, work organization, and the decision-making process leading up to the implementation of CAD were fed back to the companies. The main similarities and differences between the companies were discussed in a seminar with representatives of each company. Finally, the three case studies including questionnaire data and an analysis of the findings were published.

To reflect the commonalities and differences, the comparative analysis was undertaken in four dimensions aimed at describing the emerging organization of computer-aided design work. The first dimension was the choice of technology and the design of the technological application. The next dimension involved the organizational structures which companies develop to support the use of the new technology (the technology support 
structure). The third dimension was concerned with an analysis of how the use of CAD became a part of the existing patterns of work organization, while the final dimension was a comparison between the change processes in the three companies.

In order to facilitate the comparison, descriptive labels are used to illustrate the characteristics of development in the three companies: "detail-governed and anticipatory," "laissez-faire," and "goal-governed and pragmatic."

\section{Company A: Detail-Governed and Anticipatory}

The initiative to invest in advanced CAD/CAM technology came from the manager of the department of production technology. The technology was to be used to provide digital control information in a particular production operation, a long-standing problem area in the company. It was also thought that the new technology would facilitate integration between the production and product development functions, which had previously only had limited coordination.

Major efforts were devoted to defining the conditions for the application of the new technology. Above all, the company wished to clarify the rules and the language employed in utilizing the software before the new technology was applied on a large-scale basis throughout the company. Management determined who was to use the new technology, and for what purpose. No particular consideration was given to qualifications or interest for the technology among the engineers.

Engineers who were not assigned to CAD initially, had to wait until a decision was reached to install the new technology throughout the company. This decision was delayed repeatedly as a result of attempts to reach a high level of refinement in the system.

The technological support structure consisted of two persons, one from each of the departments involved. They kept tight control of the technology and its use. As a result of this, and because of ambitious technical standards the change process was cautious and low-key.

The emerging organization in Company A differs from that in the other two companies, particularly the degree of detailed control and analysis of the conditions required for change. These characteristics are captured in the label "detail-governed and anticipatory."

\section{Company B: Laissez-Faire}

In Company B, one of the senior engineers had followed the development in CAD-technology over a long period of time. As part of a major 
change program the managing director asked the senior engineer to investigate the possibilities of using CAD in the company and, if possible, to implement the technology within 12 months.

It was planned that all engineers in the company should become CAD-users within a few years. Therefore, major efforts were made to inform and train the engineers in the use of CAD. As a result there were twice as many potential users of CAD as there were work stations. The distribution of time on the CAD terminals was organized by the engineers themselves. For each terminal, there was a schedule to show when it was available for use.

It was in the resources devoted to the technology support structure (i.e., the organization of CAD operations and their development) that this company differed from the others and, in fact, this difference had important consequences. In Company B, the support structure was minimized by integrating support assignments into the line organization wherever possible. At the same time, considerable information and training were provided in order to reduce the potential users' fear of change. The new technology was passively adapted to the work organization. The diffusion of the use of CAD depended to a large extent on the initiative and voluntary efforts of the staff concerned.

The term "laissez-faire" could be used in describing the application of the technology and the technology support structure of this company, even if the change process itself was at least as carefully planned as in the other two companies. In economics, this term describes a situation in which the state exercises minimal control over and involvement in the economy of a country. In the case of Company B, the degree of control was low and the technological ambitions were modest. There was a preference for simple equipment which was available to many users in accordance with their needs, rather than specialized equipment employed by a few selected staff. In this respect, it was very much the opposite to what was happening in Company A.

The label "laissez-faire" describes the decentralized technology support structure and change process, the passively adaptive work organization, and the policy of making the new technology available to all engineers at the rate they and their managers thought was necessary.

\section{Company C: Goal-Governed and Pragmatic}

Developments at Company $\mathrm{C}$ differed from company $\mathrm{A}$ and $\mathrm{B}$ mainly due to a shift in strategy that occurred within the 3 -year period of CAD implementation. There was, for example, a change in direction away from a planned and controlled application of the technology toward 
greater decentralization. There was also a gradual adaption to changing circumstances.

When CAD was installed, the use of the equipment was carefully planned in 6-week schedules. Some work groups resisted and did not use the new technology at all. They argued that CAD could not improve their productivity. To get all groups to use CAD, management introduced a new way of distributing the costs of the technology. All groups had to carry their share of CAD costs. These costs could then be transferred to projects if $\mathrm{CAD}$ was used by the group. However, there was no significant change in the use of CAD until CAD terminals were decentralized and assigned to the work groups, and the support function started to develop tailor-made CAD applications to fit the needs of individuals and groups.

In Company $\mathrm{C}$, enthusiasm for the new technology, characteristic of CAD supporters in all three companies, took the form of enthusiasm about the opportunities offered by the technology, rather than excitement about the technology itself. It was felt that "the technology is what you make of it" through hard work and utilization of resources. But here, too, the new technology was taken seriously, although the stance was more pragmatic than at Company A.

There was also an interesting contrast with Company B's minimalization of resources devoted to the technological support structure. At Company $\mathrm{C}$, considerable investments were made and there was a tendency to maximize organization, through extensive planning and control, rather than to minimize it. While there were more CAD-users in the company, there were twice as many support persons per CAD-user in Company $\mathrm{C}$ compared to Company B (0.4 vs. 0.2$)$. There were also signs of organizational learning, in as much as the forms for planning changed and detailed control was reduced. One example is the "user group" that was founded with representatives from every group of engineers within the design department. In this group, information and user-requests could be exchanged between CAD-users and support personnel.

At Company $\mathrm{C}$, the process was more dynamic and expansive, partly as a result of the relatively heavy emphasis on the technological support structure. The technological system was gradually extended and the use of CAD increased noticeably when applications programming commenced.

The emerging organization in Company $\mathrm{C}$ is characterized as "goal-governed and pragmatic" because the application of the technology focused on support to existing practices of design work, the technological support structure changed from being control-oriented to being learningoriented, because the work organization was adjusted actively through 
extensive support and tailor-made solutions, and because the change process triggered by the new technology extended outward.

\section{CONCLUSIONS FROM PHASE 1}

Did the organization change when CAD was introduced? To answer this question we need to distinguish between formal organization and real patterns of action. The formal organization remained unchanged during the introduction of CAD. This observation is in line with what has been reported in other European studies (Wingert, et al. 1984; Francis, 1982; Forslin, et al. 1989; Ebel \& Ulrich, 1987). At the same time, the introduction of the new technology triggered effects other than changes of formal work organization.

In the 3-year period following the introduction of CAD, the designers who used the equipment gradually changed their way of working. Pre-planning of work increased, while at the same time there was greater flexibility in the actual drawing operations. The individual's control of his or her work decreased due to greater dependence on technical and organizational systems, but capacity, in terms of the speed of making drawings, calculations, etc., increased. All these factors influenced the designers' daily work, and also their experience and familiarity with assignments. A shift in the content of the work, and therefore in the knowledge required, seemed to have taken place, with the focus shifting from product design onto the work process itself and the methods employed.

As a result of the introduction of CAD, the division of duties between the various design engineers acquired a new dimension. Should a job or project be undertaken manually or with CAD, and by whom? But although the work process was gradually modified, the formal work organization did not change. New work tasks arose primarily in connection with the operation, maintenance, and development of the technical equipment. The way this support structure was organized differed between the companies.

One important conclusion from the study was that although no changes in the formal organization were found, the way people carry out their work is likely to change. Furthermore while there were many similarities, the companies seem to have organized computeraided design work in different ways.

The causes of these gradual changes and inter-company differences may be found in people's day-to-day actions, as observed in Barley's (1986) study. They may also be traced to the organizing frameworks held by significant actors in the organizing process, which is the locus of the investigation in the parts to follow. 


\section{PHASE 2: A STUDY OF ORGANIZING FRAMEWORKS AMONG ACTORS IN THE THREE CHANGE PROCESSES}

\section{Method}

A study focusing on significant actors was designed to trace explanations for the differences between the three emerging organizations in Companies A, B, and C. Data was collected in two and sometimes three interviews per person. Each interview lasted approximately 2 hours. The first interview was aimed at getting a description of the process of introducing CAD in the company and the interviewee's role in this process. At the beginning of the second interview, interviewees were presented with a design task, which is described below. They were also asked questions about their personal background, attitudes toward change, and decision-making style.

If the structural formation of organizations is the result of individual actions based on subjective and local rationalities, it is important to generate data about the actors' organizing frameworks without introducing the accepted organization theory perspective into the research setting. The aim was to investigate the ideas of a number of actors about organization and organizing as expressed in their own terms, and to expose the relevant differences between the organizing frameworks of these individuals. Thus it was necessary to find representations of the actors' organizing frameworks which were independent from their observations of the emergent organization in the three cases described earlier. Mutually independent observations are essential if there is to be any meaningful discussion of the similarities and possible interactive influences of the variables. In the study, this was achieved by using independent data sources. In order to arrive at intersubjective case descriptions of change processes and emerging organization in the three companies, the case studies relied on interviews, questionnaires, and detailed process descriptions discussed with company representatives as described above.

This study was designed to uncover the implicit assumptions of the most important actors in the three organizing processes. It aimed at a description of these persons' organizing frameworks, their generalized way of thinking about organizing, not at a description of their particular organization. It was assumed that by uncovering these generalized, implicit thought structures, data would be obtained which were as independent of the intersubjective case descriptions of emerging organization as could possibly be hoped for.

People use different cognitive structures for different situations, or even different structures in the same situation. Zajonc (1960) has called this cognitive tuning. This phenomenon has consequences for the methodology 
applied in studies of cognitive structures. Three things are important in trying to collect data to represent the elements and structures in question. The stimuli which generate the research data should involve objects, the phenomena or events investigated should be as close as possible to the object of study, and the respondent should be placed in an information transfer situation which resembles real life. Furthermore, the respondents' associations and descriptions should be collected with minimal interference from the researcher.

To meet these criteria, a method was used to generate data about the actors' organizing frameworks that had been employed previously in a study of cognitive consequences of a person's position in a communication network (Zajonc \& Wolfe, 1966). This method primarily generates data about how well developed and differentiated such frameworks are in a given area.

The interviewees were given a task (Appendix) designed to generate the concepts which they used to understand and solve the task. The task asked them to design the organization of a design and development operation in a new company. No background information was provided about the company's financial and technological status, personnel, or other factors. In order to encourage interviewees to express themselves clearly and in simple terms, they were asked to imagine they were to make a presentation to people who knew nothing about organizations (for example a delegation from an alien culture). They were then asked to list the concepts or key words that their presentation was built around. The concepts were written down on a form and shown to the interviewee who then divided them into groups and subgroups to reflect how these concepts were related. Subsequently, the interviewee was asked to differentiate between the concepts by indicating their importance on a 5-point scale.

The organizing task made it possible to analyze the complexity of organizing frameworks in terms of their constituent elements and their interrelations. For this analysis, an indicator $(\mathrm{CI})$ was developed which measures the number of elements in each construct and the extent to which the organizing framework contains elements of differing importance. ${ }^{3}$

${ }^{3}$ The indicator for the complexity of the organizing framework (CI) was weighted in accordance with the following formula:

$$
\mathrm{CI}=\operatorname{Sum}_{k=1}^{n} \frac{e}{5-r}
$$

where $k$ represents constructs, $e$ is the number of elements in a construct and $r$ is the number of steps used by the respondent on the 5-point of importance, minus one. 
The content could also be evaluated by analyzing the concepts used and the way they were grouped into constructs. This analysis was more interpretative in nature. After careful investigation of the frameworks, a classification schema was developed. Each construct was assigned to one of the following categories: assumptions, solutions, process, or outcome. Since about half of the constructs were categorized as solutions, this group was further divided into subgroups under the following headings: structure, control systems, technology, and relations/communication.

The classification was carried out by the author and one of his colleagues independently. This resulted in a $94 \%$ correspondence on a total 165 elements. The classification was then reviewed and adjusted.

There were no difficulties in selecting actors that had been significant in the processes studied. The people to be included in the actors study were selected after listening to interviewees' descriptions of the introduction of the new technology, i.e., phase 1 of the study. The interviewees all named the same people, in total ten individuals in the three companies, who had figured prominently in the introduction process. They all had similar job functions. They were the heads of the design departments, the project leaders of the CAD projects, who later became managers of CAD operations, and a top-level manager in each company. Because Company A also had a CAM-application (computer aided manufacturing) there was a CAM manager in addition to the CAD manager.

\section{Complexity in Organizing Frameworks}

Cognitive complexity and people's abilities to differentiate between concepts, their importance, and their interrelation is regarded as a major resource and as the foundation of competence in any given area. In this study, the complexity of the actors' organizing frameworks was analyzed by the complexity indicator $(\mathrm{CI})$ which took into account elements, groups of elements (constructs), and the weight given to each element in the organizing framework.

The results of the study indicate that the number of elements in actors frameworks ranged from 10 to 25 and the number of constructs from 4 to 10. Organizing frameworks of line managers $(n=5)$ contained, on average, more elements (17.4) than those of personnel $(n=4)$ responsible for CAD (15.3). ${ }^{4}$ There is a similar difference in the case of the more complicated

\footnotetext{
${ }^{4}$ In cases where a difference in average values between two groups of people is claimed, statistical tests for significance have been carried out. $T$-tests confirm differences at the 0.05 level. It was assumed that the observations are drawn from independent, normally-distributed populations with equal standard deviations. In fact, the observations are not a sample but refer, almost exclusively, to total populations. This does not disqualify the test, but it may mean that testing was unnecessary.
} 
complexity indicator $(\mathrm{CI})$. This demonstrates that the managers had greater organizing competence than staff responsible for the technology. According to Zajonc and Wolfe (1966), there is a correlation between an individual's position in the organization and the complexity of his image of the organization. It is interesting to note that even greater differences can be observed between the means in the complexity indicator $\mathrm{CI}$ of the principal actors in the companies:

$$
\begin{aligned}
& \text { Company } \mathrm{A} \mathrm{CI}=4.8 \\
& \text { Company } \mathrm{B} \mathrm{CI}=4.0 \\
& \text { Company } \mathrm{C} \mathrm{CI}=5.4
\end{aligned}
$$

There are appreciable differences between Company B and the other two companies. If the material is limited to staff responsible for CAD and line managers, there are also appreciable differences between Company $\mathrm{A}$ and Company C.

In view of these indications of varying degrees of organizing competence in the principal actors, it seemed appropriate to take the analysis one step further and ask whether there were also differences in the content of the organizing frameworks.

\section{Contents of Organizing Frameworks}

Since technological choice was central to the change process, it was anticipated that technology would dominate the actors' ideas about organizing. This was not borne out by the data. Only one of the actors included technological aspects in his organizing framework, and this was interpreted as implying that the actors did not have any integrated frameworks of technological and organizational change. The absence of a framework in which technology and organization are coordinated may well explain the technocratic character of the organizing processes.

As Tables II and III indicate, there were differences in the content of the organizing frameworks in the three companies. In Company $\mathrm{C}$, key actors held relatively well-developed ideas about organizational solutions and the change process. In Company A, organizing frameworks of key actors relied more heavily on organizational assumptions, while in Company $\mathrm{B}$, frameworks were generally less fully developed, even if there were some constructs about the outcome of the process. More than $60 \%$ of the constructs expressed by those responsible for the introduction of the new technology in Company $\mathrm{C}$ were solution-oriented. Organization was seen as a means of arriving at solutions to problems (i.e., action), rather than as a means of studying the conditions or the outcomes of action. 
Table II. Average Numbers of Elements in Actors Organizing Frameworks, Broken Down by Type of Construct

\begin{tabular}{lccccc}
\hline & Assumption & Solution & Process & Outcome & Elements/actor \\
\hline Company A & 8.5 & 6 & 1 & 0 & 15.5 \\
Company B & 3.7 & 7 & 1 & 1 & 12.7 \\
Company C & 2.3 & 12.3 & 4.3 & 0 & 19.0 \\
\hline
\end{tabular}

Table III. Average Number of Elements in the Actors' Organizing Frameworks, Solution-Oriented Constructs Only

\begin{tabular}{lcccc}
\hline \multicolumn{5}{c}{} \\
& Structure & Control-system & Technology & Human relations \\
\hline & & & & \\
Company A & 2.3 & 2.3 & 0 & 1.5 \\
Company B & 4.3 & 0.7 & 1 & 1 \\
Company C & 5.3 & 3.7 & 0 & 3.3 \\
\hline
\end{tabular}

\section{Analysts, Facilitators, and Organizers}

As in the analysis of the emerging organizations, descriptive labels are employed to summarize the differences in the actors' cognitions. On the whole, analysis of the data produced a pattern which indicates differences in organizing frameworks between companies and between managers and specialists. Brunsson (1985) has described the difference between decision rationality and action rationality, a distinction which illustrates the differences between the actors covered by the present study. In accordance with Brunsson's terminology, the actors in Company A could be described as decision rational, while actors in Company $\mathrm{C}$ tended to be more action rational in their organizing frameworks. The actors in Company B cannot be said to have shown either decision rationality or action rationality. The more passive attitude of the actors in Company B suggests a rationality which consists of "letting things happen" rather than attempting to control them.

What emerges from this analysis is a typology in embryonic form of the actors in organization processes. Actors who are principally characterized by their attempts to achieve decision rationality - trying to do things right - seem to function mainly as Analysts. In contrast, actors characterized by action rationality - getting things done - become Organizers in organizing processes. Actors who let things happen without necessarily attempting to control them are Facilitators and their role is mostly to keep the process moving. 
In Company $\mathrm{A}$, staff responsible for CAD showed a preponderance of assumptions in their responses. This, combined with their limited organizing competence, leads to the classification of Analysts. Their role in a change process of this type is mainly that of investigator, rather than that of the agent of change. The design manager in Company A might also be seen as an Analyst, even if his organizing framework was solution-oriented. Most of the solution elements in his organizing framework were of the control-systems type which require prior investigation and development efforts if successful solutions to organizational problems are to be found.

The solutions orientation of the actors in Company $\mathrm{C}$, combined with a relatively well-developed organizing competence on the part of those with line and technology responsibilities, leads to the classification of Organizers. Their positive attitudes to change indicate innovative ability. In other words, they have the potential to function as organizers in a project and as innovators in an ongoing change process.

In Company B the design manager had organizing frameworks which resembled those of the "Organizers," even if complexity, the indicator of organizational competence, was much lower. With this profile, the design manager would not be expected to have actively pursued the role of organizer in an organizing process. The content of the organizing frameworks among the principal actors in Company B varied, and organizing competence was lower than in the other two companies. A further difference was that none of the actors had solution constructs in the controlsystem category.

\section{ORGANIZING FRAMEWORKS AND EMERGING ORGANIZATIONS - A COMPARISON}

The fundamental question in this two-phase analysis was whether the organizational forms emerging in the organizing processes corresponded to the organizing frameworks of the principal actors. A comparative analysis produced empirical evidence to support this hypothesis. Thus, the results support a correlation between human cognitive structures such as the organizing frameworks considered in this piece of research, and the structure of organizations, as suggested in the literature (Downey \& Brief, 1986).

The parallel between the organizations which emerged in the three cases ("detail governed and anticipatory," "laissez-faire," and "goal governed and pragmatic") and the contents of the actors' organizing frameworks ("Analysts," "Facilitators," and "Organizers") is a key argument is assuming such a correspondence (Table IV). This is seen primarily in 
Table IV. A Comparison Between Emerging Organization and Organizing Frameworks Among Key Actors in Three Companies

\begin{tabular}{|c|c|c|}
\hline & $\begin{array}{l}\text { The actors' organizing } \\
\text { frameworks }\end{array}$ & $\begin{array}{l}\text { Emerging } \\
\text { organization }\end{array}$ \\
\hline $\begin{array}{l}\text { Company A: } \\
\text { Company B: } \\
\text { Company C: }\end{array}$ & $\begin{array}{l}\text { "Analysts" } \\
\text { "Facilitators" } \\
\text { "Organizers" }\end{array}$ & $\begin{array}{l}\text { "Detail governed and anticipatory" } \\
\text { "Laissez-faire" } \\
\text { "Goal governed and pragmatic" }\end{array}$ \\
\hline
\end{tabular}

the predominance of assumptions and analysis in the organizing frameworks in Company A, which corresponds to the detail-governed and anticipatory character of the emerging organization. It is also seen in the cognitive orientation observed in company $\mathrm{C}$ which favors solutions and practical action in keeping with the goal-governed and pragmatic nature of its emerging organization. The notion also conforms with the observation that the change process in Company $\mathrm{C}$ had not terminated, despite changing conditions, while Company A concentrated on the technological factors presumed to be required for the systematic application of technology.

Another key argument in support of my conclusion is that observed differences in the cognitive complexity of organizing frameworks were reflected in the degree of conscious organizing the companies engaged in. These differences were most apparent in the case of Company B and Company $\mathrm{C}$. The observations indicate a close correlation between the degree of planning and organization in technological/organizational change and organizing competence. In Company $\mathrm{C}$, the principal actors in the organizing process had much more elaborate organizing frameworks (an important indicator of such competence) than the actors in Company B.

\section{A COGNITIVE ACTORS APPROACH TO ORGANIZATIONAL CHANGE}

Conclusions from an aggregated study of this kind must be treated with some caution. Could it be the case that the differences observed reflect the actors' learning from participation in their respective organizing processes? If so, the differences between the actors would be the result of developments in the companies rather than their cause.

It is not possible to give a conclusive answer on the basis of the present data. However, the interpretation given here of the processes observed during a 3 year period of implementing new technology, is based on the belief that the organizing that took place may be compared with relatively 
stable cognitive structures. As was pointed out earlier, cognitive structures are relatively stable. One argument in favor of the relative stability of the actors' organizing frameworks is their agreement with actors' cognitive styles (Löwstedt, 1989). From a theoretical point of view, cognitive styles represent stable characteristics regarding human learning and problem solving. It might be possible, therefore, to speak of actor styles in organizing processes, and to classify actors in accordance with the proposed typology.

\section{Analysts, Facilitators, and Organizers}

A situation in which one or two individuals are entrusted with the execution of a change such as the one described in this study, cannot be considered in an organizational vacuum. If problem solving and organizational choices are regarded as the result of a conflux of problems, solutions, participants, and reasons for decisions (Cohen et al., 1972), then the actors are located in an organizing process in an organizational context. Their free will is limited and their reproduction of ideas and structures is dependent on problems and situations.

In the case of the introduction of CAD in the three companies, the technology can be seen as a solution for which problems were sought, rather than as the solution of a problem. In time, as it was developed organizationally and in software terms, the tool became the solution for problems that needed to be solved. The investment in CAD technology, and the emergence of particular individuals as the principal actors in the organizing processes, was not just coincidental or a matter of having enough time for new assignments. Such developments do not take place if senior management does not have confidence in the competence and strength of the individuals in question. Hence, these individuals and the new technology may both be regarded as candidates which the organization considered suitable to foster a desired organizational change ("Strategic Candidates," Stymne, 1974). The idea that organizing processes at higher hierarchical levels select actors for processes at lower levels lends further support to the argument that differences between the actors' organizing frameworks do not necessarily occur as a result of their participation in the organizing process.

Reference has already been made to Giddens' (1984) idea that emerging structures are influenced by existing structures. In his study of hospital laboratories, Barley (1986) claimed that the structuring of organizations is mainly determined by existing structures - existing action patterns - and by human interactions in the work process. According to Barley, both new technology and the decision-makers inevitably produce opportunities for people to change action patterns in interaction with each other, and hence 
also to change structures. Since the experience gained in this study of engineering companies is quite different, in that it suggests that actors' organizing frameworks may very well affect the organization of work, there is a need for a distinction between different types of change in order to be able to interpret such different observations.

It may be the case, in line with Barley's research, that gradually emerging organization structures, involving for example the introduction of new technological aids at work and other everyday rationalization measures, are chiefly determined by the interaction between the individuals concerned and their ideas about how the work should be carried out. In the case of the engineering companies, on the other hand, where the organizing processes were characterized by organizational design, i.e., new activities and functions being designed in a more or less conscious way, the actors' organizing competence and the contents of their organizational frameworks were crucial for the organizational structures which developed. Where it is a question of planned organizational change, i.e., organizational development efforts or other planned changes in the formal structure, the role of organizing frameworks and organizing competence are probably as important as in organizational design. However, the explicit nature of such changes may result in a greater impact of power-based and financial rationalities on the actors' discussions in the change process, and therefore on the new structures, than the often unarticulated processes reported here.

In contrast with planned change processes, organizational design processes and the gradual emergence of new structures do not necessarily have to involve a conscious striving for change. Looking at organizational development in terms of ongoing organizing processes is to assume that an organization is in a state of continuous change. Human actions in organizations are like the water in Heraclitus' stream: Panta rhei - everything is in motion. Detailed analysis of organizational structures reveals that these structures are merely approximations of the action patterns. Therefore a conceptual apparatus is required to describe and analyze the different forms of organizational changes in terms of the extent to which conscious and planned interventions determine the shift to altered action patterns. In such a conceptual apparatus, analysis would proceed on three levels.

The first level to consider is normative. It is expressed in the formal organization, i.e., in formal rules, plans, policies, and efforts by management to describe and steer actions and thinking in the organization in a given direction. Thus, this level is concerned with how things ought to be in the organization. 
Table V. A Conceptual Apparatus For Description and Analysis of Organizing Processes

\begin{tabular}{llll}
\hline & Structure & Process \\
\hline Cognition & Organizing framework & $\begin{array}{c}\text { Dominant } \\
\text { organization idea }\end{array}$ & $\begin{array}{c}\text { Learning } \\
\text { Social } \\
\text { Experience based }\end{array}$ \\
& Organization image & Local theory & \\
\hline
\end{tabular}

$\begin{array}{lll}\text { Real organization } & \begin{array}{l}\text { Real work } \\ \text { Patterns of actions in the work process }\end{array} & \begin{array}{c}\text { Change process } \\ \text { Actions for and } \\ \text { against change }\end{array}\end{array}$

$\begin{array}{lll}\begin{array}{l}\text { Formal } \\ \text { organization }\end{array} & \begin{array}{l}\text { Work organization } \\ \text { Organization chart, job descriptions, } \\ \text { manuals, etc. }\end{array} & \begin{array}{l}\text { Planned change } \\ \text { Plans, rules, } \\ \text { project-groups for } \\ \text { change }\end{array} \\ & & \begin{array}{l}\text { chang } \\ \end{array}\end{array}$

The formal level needs to be distinguished from the second level of analysis, which is concerned with what actually happens, in other words, human actions. Actions do not occur at random, but are structured on the basis of local circumstances and restrictions, in terms of the prevailing structures for action and thought. Actions on the second level of analysis correspond in varying degrees to the norms expressed in the formal organization.

The third level of analysis of organizations in a state of change is concerned with the perceptions of individuals. It focuses on their image of how the organization is structured and how it functions, and on their evaluations of the organization. Ultimately, this level deals with individuals' way of creating a meaning of how things are and how they should be, that is to say their understanding and knowledge of the first two levels (norms and actions). This third level is the cognitive level.

Hitherto, mainly the conceptual apparatus for structures on the cognitive level has been discussed. Table $V$ shows how these concepts are combined with the concepts selected for the formal and real levels of analysis.

To summarize, the organizing process can be seen as an ongoing process in which people act and interact on the basis of their own organizational frameworks. This process becomes more focused (and easier to study) when the organization is faced with technological, personal, environmental, or other externally generated changes. Such factors may prove to have a catalytic effect on organizing processes. In cases of 
technological change, choosing the right technology becomes the arena in which the organizing process is played out by the actors involved. Organizing processes may, however, be studied also in the absence of such catalytic factors, for example, by means of longitudinal observation of work processes.

The view staff members have of the organization in which they work (their image of the organization), and how it might be changed and why, is personal and based on each individual's subjective rationality. This rationality is based, in turn, on the individual's knowledge and experience of organizations and organizing (the organizing framework), and also on interaction with others and on local theories (joint frameworks about the organization and its functioning), as expressed in dayto-day communication between members of the organization. The organizing process may also be affected by dominant ideas about organizational structure which consist of or derive from the organizing frameworks of dominant actors.

\section{SUMMARY AND CONCLUSION}

The main purpose of this study was to find out more about organizing frameworks and their importance for organizational change. For this, it was necessary to make a distinction between planned organizational change, organizational design, and emerging organization. The fact that no change in formal organization was observed in conjunction with the introduction of CAD threw into relief the differences between the formal (norms), real (actions), and cognitive (thoughts) levels in the analysis of organizations.

Data from three companies where computer-aided design was introduced suggested a gestalt in the structures of three emerging organizations. A comparative analysis of the emerging organizations, and of the complexity and content of actors' organizing frameworks, showed close correspondences. Analysts, Facilitators, and Organizers seem to affect organizing processes in such a way as to give rise to different organizations. The results therefore support the hypothesis, often put forward by organization theorists, that human cognitive structures will affect how organizations are structured.

Many questions remain unanswered in this growing area of organizational research. Further research is required, for example, to develop the typology outlined in this paper, as well as our understanding of organizing frameworks and other cognitive structures of actors in organizing processes. Other questions concern the interaction between actors in organizing processes and the interaction between their images of the 
organization and local theories of best practice. Such research would lead to a better understanding of the reasons for ongoing or completed changes, but would also provide insights into how to arrive at more efficient methods and ways of undertaking change efforts.

\section{APPENDIX. \\ THE DESIGN TASK}

The following instructions were given to participants:

In this research project we want to compare the introduction of CAD in three companies. Therefore we ask you and some of your colleagues who have participated in this process to complete some questionnaires.

Your participation will allow us to investigate differences among decision makers in the way they look at change and decision making.

Your answer is confidential and will not be shown to anyone. The results of this study will be grouped in such a way that their presentation is anonymous and describes differences and similarities between groups of decision-makers in the three companies, not between individuals.

\section{INSTRUCTION}

Assume you are in a situation where your assignment is to organize the Design and Development of a new company. This department is to be staffed by some $50-100$ people.

Assume also that your company is being visited by a delegation of people from a very different culture, and that you have been asked to present to them your work with the Design task. They do not know anything about organizations, therefore they ask you to give a short and concise presentation.

Please mention the variables, terms, or concepts you have to use to make the department run successfully.

1. Please tell me one concept at a time so that I can write them down.

* When this task is completed:

2. Sort these concepts into groups in any way you think makes sense.

* When this task is completed:

3. On the next sheet you will find the concepts you mentioned and a scale from 1-5, to sort out how important you think they are. Please rate the concepts in terms of their importance $(5=$ very important, $1=$ not important at all $)$.

After this was completed, the interviewees were asked to what degree the phenomena mentioned as concept helped or hindered the process of introducing CAD in the company. They were also asked to fill in questionnaires about attitudes to change and cognitive style. The data obtained in this phase of the study have not been included in the present discussion. 


\section{ACKNOWLEDGMENTS}

I would like to thank Jane Dutton, Dennis Gioia, Lance Sanderlands, Rami Shani, colleagues at Templeton College, Oxford, where I recently spent a sabbatical, and two anonymous reviewers of Human Relations for their comments on earlier versions of this paper. This research has been supported by grants from the Swedish Council for Research in the Humanities and Social Sciences.

\section{REFERENCES}

ARGYRIS, C., \& SCHÖN, D., Organizational learning: $A$ theory of action perspective. Reading: Addison-Wesley, 1978.

ATKINSON, R., ATKINSON R., \& HILGARD, E., Introduction to psychology (8th Ed.). San Diego: Harcourt Brace Jovanovich, 1983.

BANDURA, A., Social learning theory. New York: Prentice-Hall, 1977.

BARLEY, S., Technology as an occasion for structuring: Evidence from observations of CT scanners and the social order of radiology departments. Administrative Science Quarterly, 1986, 31, 78-108.

BERNER, B., Teknikens värld. Lund: Arkiv, 1981.

BOWEY, A. Myths and theories of organization: The impact of organizational interpretations. International Studies of Man and Organizations, 1983, 13, 69-91.

BRIEF, A., \& DOWNEY, K. Cognitive and organizational structures: A conceptual analysis of implicit organizing theories. Human Relations, 1983, 36, 1065-1090.

BRUNSSON, N., The irrational organization: Irrationality as a basis for organizational action and change. New York: Wiley \& Sons, 1985.

BRYTTING, T., \& LÖWSTEDT, J. Organisationsfrihet - visst finns den! Ny teknik och andra faktorers betydelse for arbetsorganisation och arbetsroller $i$ sjukhuslaboratorier. Stockholm: EFI, 1986.

CHILD, J. Organizational structure, environment and performance: The role of strategic choice. Sociology, 1972, 6, 1-22.

CHILD, J., GANTER, H-D., \& KIESER, A. Technological innovation and organizational conservatism. J. Pennings and A. Buitendam (Eds.), New Technology as Organizational Innovation. Cambridge: Ballinger, 1987.

CHILD, J., \& LOVERIDGE R. Information technology in European services. Oxford: Basil Blackwell, 1990.

COHEN, M., MARCH, J.G., \& OLSEN, J. A garbage can model of organizational choice. Administrative Science Quarterly, 1972, 17, 1-25.

COOLEY, M. Impact of CAD on the designer and the design function. Computer Aided Design, 1977, 9, 273-281.

CROZIER, M., \& FRIEDBERG, E. Actors and systems. Chicago, 1980.

DANIELSSON, A. Företagsekonomi en översikt. Lund: Studentlitteratur, 1983.

DOWNEY, K., \& BRIEF, A. How cognitive structures affect organizational design. In H. Sims, D. Gioia, and Associates (Eds.), The Thinking Organization. San Francisco: Jossey-Bass, 1986.

EBEL, K-H., \& ULRICH, E. The computer in design and manufacturing: Servant or master? Genevea: ILO, 1987.

EDQUIST, C., \& EDQVIST, O. Sociala Barare av Teknik. Brygga Mellan Förändring och Samhällsstruktur. Zenit Häften No. 5, 1980.

FINNE, H. Mellom Tegnebrett og Terminal. Institutt for industriell miljöforskning, SINTEF-NTH, 1982.

FISKE, S., \& TAYLOR, S. Social cognition. New York: Random House, 1984. 
FORSLIN, J., THULESTEDT, B-M., \& ANDERSSON, S. Datorstödd konstruktion. En fallstudie vid Volvo Flygmotor. Stockholm: FArådet, 1985.

FRANCIS, A. The Impact of information technology at work. In M. Bannon (Eds.), Information technology: Impact on the way of life. Dublin, 1982.

FREEMAN, L., FREEMAN, S., \& MICHAELSON, A. On human social intelligence. Journal of Social Biological Structures, 1988, 11, 415-425.

GIDDENS, A. The constitution of society: Outline of the theory of structuration. Cambridge: Polity Press, 1984.

HELGESON, B. Arbete teknik ekonomi: Förståelseformer inom modern industrisociologi. Tekniska Högskolan i Luleå, Luleå, 1986.

HUFF, A. (Ed.), Mapping strategic thought. Chichester: John Wiley and Sons, 1990.

KELLEY, H. H. Attribution in social action. Morristown: General Learning Press, 1977.

KELLY, G. A. The Psychology of personal constructs. New York: W.W. Norton \& Company, 1955.

KOLB, D. A. Management and the learning process. California Management Review, 1976, $18,21-31$.

LAUKKANEN, M. Describing management cognition: The cause mapping approach. Scandinavian Journal of Management, 1990, 6, 197-216.

LÖWSTEDT, J. Contingencies or cognitions? Two paths for research on organization and technology. Scandinavian Journal of Management Studies, 1985, 1, 207-225.

LÖWSTEDT, J. Automation eller kunskapsproduktion? Stockholm: EFI, 1986.

LÖWSTEDT, J. Prejudices and wishful thinking about computer aided design. New Technology, Work and Employment, 1988, 3, 30-37.

LÖWSTEDT, J. Föreställningar, ny teknik och föråndring. Lund: Doxa, 1989.

MEREDITH, J. R., \& HILL, M. M. Justifying new manufacturing systems: A managerial approach, Sloan Management Review, Summer 1987, 49-61.

MILLER, G. A. The magical number seven plus minus two: Some limits on our capacity for processing information. Psychological Review, 1956, 63, 81-97.

NEMETZ, P. L., \& FRY L. W. Flexible manufacturing organizations: Implications for strategy formulation and organization design, Academy of Management Review, 1988, 13, 627-638.

PERROW, C. A framework for the comparative analysis of organizations. American Sociological Review, 1967, 32, 194-208.

PERSSON, B. Surviving failures. Stockholm: Almqvist \& Wiksell, 1979.

SCHREYÖGG, G. Contingency and choice in organization theory. Organization Studies, 1980, $1,305-326$.

SCOTT, W. A. Cognitive structure and social structure: Some concepts and relationships. In I. Washburne (Ed.), Decisions values and groups. 1962.

SILVERMAN, D. The theory of organizations. London: Heineman, 1970.

SIMON, H. A. A formal theory of interaction in social groups. American Sociological Review, 1952, 17, 202-211.

SKOGH, G. Företagets kontrakt. Stockholm: SNS, 1989.

STYMNE, B. A Behavioral Theory of Strategy Formation. EIASM-SIAR Seminar on Strategic Management, Köpenhamn, 1974.

THORNDYKE, E. L. A constant error in psychological ratings. Journal of Applied Psychology, 1920, 25-29.

TOLMAN, E. C. Cognitive maps in rats and men. Psychological Review, 1948, 55, 189-208.

TRIST, E. L., \& BAMFORTH, K. W. Some social and psychological consequences of the long-wall method of coal-getting. Human Relations, 1951, 4, 3-38.

TRIST, E. L., HIGGIN, G. W., MURRAY, H., \& POLLOCK, S. B. Organizational choice. London: Tavistock Publications, 1963.

TVERSKY, A., \& KAHNEMAN, D. Judgement under uncertainty: Heuristics and biases. Science, 1974, 1124-1131.

WASON, P. C. On the failure to eliminate hypotheses in a conceptual task. The Quarterly Journal of Experimental Psychology, 1960, 12, 129-140.

WEICK, K. E., \& BOUGON, M. G. Organizations as cognitive maps. J. Sims, D. Gioia, and Associates (Eds.), The thinking organization. San Francisco: Jossey-Bass, 1986. 
WINGERT, B., DUUS, W., RADER, M., \& REIHM, U. Cad im maschinenbau: Wirkungen, chancen, risken. Berlin: Springer-Verlag, 1984.

WITKIN, H. A., DYK, R. B., FATERSON, H. F., GOODENOUGH, D. R., \& KARP, S. A. Psychological differentiation: Studies of development. New York: Wiley \& Sons, 1962.

ZAJONC, R. The process of cognitive tuning in communications. Journal of Abnormal and Social Psychology, 1960, 61, 159-167.

ZAJONC, R., \& WOLFE, D. M. Cognitive consequences of a person's position in a formal organization. Human Relations, 1966, 19, 139-150.

\section{BIOGRAPHICAL NOTE}

JAN LÖWSTEDT is associate professor at the Stockholm School of Economics. He received his $\mathrm{PhD}$ in Organization theory from the same school. His research activities focus on organizational thought and cognition, organizational change, and the diffusion of technology. 